\title{
BioRxiv bankrolled
}

\section{Facebook couple commits undisclosed amount to develop open-access biology preprint server.}

\section{BY EWEN CALLAWAY}

$\mathrm{B}$ ioRxiv, the hub for preliminary versions of biology research papers, has announced that it will begin receiving "significant" financial support from the Chan Zuckerberg Initiative (CZI), a philanthropic effort started by Facebook co-founder Mark Zuckerberg and his physician wife Priscilla Chan.

The multi-year funding package - terms of which have not been disclosed - will pay for staff, technology development and other infrastructure at bioRxiv, says John Inglis, the executive director of Cold Spring Harbor Laboratory Press and co-founder of the 3-yearold site, which posted its 10,000th manuscript last month.

Chan and Zuckerberg created the CZI in 2015, and a year later made a US\$3-billion commitment to support basic research with the aim of curing, preventing and managing "all disease" in their children's lifetime. "They're interested in anything that accelerates the pace of research, and bioRxiv was on their radar from the beginning," says Inglis.

\section{FRIENDLY FORMATS}

At the top of Inglis's wish list is an automated tool to translate scientific papers posted to bioRxiv, often as word-processor files or PDF documents, into more web-friendly formats, such as XML. That would make papers more readable on smartphones and tablets, but also more amenable to text mining - an approach increasingly used in scientific analyses.

Inglis intends to create application programming interfaces, or APIs, to make bioRxiv content more accessible to other software developers. He is also eager for bioRxiv to collaborate with a start-up acquired in January by the CZI called Meta, which uses artificial intelligence to probe the scientific literature.

BioRxiv currently relies on commercial software from HighWire Press. However, any software developed with CZI funding will be open source, says Inglis. And, he adds, "we are committed to moving toward an open-source platform" for the rest of the site.

That move would satisfy one of the requirements of a central life-sciences preprint service, which has been called for by funders such as the US National Institutes of Health and the Wellcome Trust.

Jessica Polka, director of ASAPbio, a grass-roots organization leading the charge for a central preprint site, welcomes news of the CZI investment. She says the deal between bioRxiv and the CZI will be a boon to the preprint ecosystem. "We share the same goals of promoting efficient and rapid scholarly communication," she says.

\section{CORRECTION}

The News story 'Stem-cell bet faces big test' (Nature 544, 401-402; 2017) erred in locating John Simpson in Washington DC. In fact, he is based in Santa Monica, California. 